\title{
New insights into surface-functionalized swelling high charged micas: Their adsorption performance for non-ionic organic pollutants
}

M. Carolina Pazos, ${ }^{1}$ Miguel A. Castro, ${ }^{2}$ Agustín Cota, ${ }^{3}$ Francisco J. Osuna, ${ }^{2}$ Esperanza Pavón, ${ }^{4}$ María D. Alba ${ }^{* *}, 2$

${ }^{1}$ Escuela de Ciencias Químicas, Universidad Pedagógica y Tecnológica de Colombia, UPTC. Avda. Central del Norte, Via Paipa Tunja, 39-115,Boyacá, Colombia.

${ }^{2}$ Instituto Ciencia de Materiales de Sevilla (CSIC-US). Avda. Américo Vespucio, 49.41092-Sevilla, Spain

${ }^{3}$ Laboratorio de Rayos-X. CITIUS. Avda. Reina Mercedes, 4. 41012-Sevilla, Spain

${ }^{4}$ Center for the Development of Nanoscience and Nanotechnology, 9170124-Santiago, Chile

\section{Abstract}

The major components of the wastewater from the petroleum refineries are benzene, toluene and phenol and one of the techniques applied to the treatment of effluents is sorption using organo-functionalized clay. The materials exploited in the present study are a family of surface-functionalized synthetic micas and their sorption capacities for non-ionic organic pollutants are analyzed. The organo-functionalization of their surface provides them the capacity to sorb effectively non-ionic pollutants in the interface. Their adsorption performance is a function of the alkylamonium properties such as the chain

\footnotetext{
${ }^{*}$ Corresponding author

E-mail: alba@icmse.csic.es
} 
length, the mass fraction and the organization of the organic cation in the interlayer space of the micas.

Keywords. Organo-functionalization, organic pollutants, sorption isotherm, interface adsorption. 


\section{Introduction}

Effluents from petrochemical industries and oil refineries are the major sources of hazardous wastes. Among the organic pollutants present in these effluents, phenol stands out; however, there are also other lighter non-ionic hydrocarbons (NOCs) such as benzene, toluene, ethylbenzene and xylene (BTEX) that have higher solubility in water. In fact, volatile organic compounds, VOCs, are known to be among the major contributors to risk for health damage and serious environmental problems [1].

Activated carbon and hydrophobic zeolites are the most widespread alternative to eliminate the VOCs due to its developed microporosity that ensures good sorption capacities [2-4]. However, its application is limited: activated carbon is thermal and chemical instable, causing significant safety problems. Hydrophobic zeolites are ten times more expensive and sensitive to the presence of humidity [5]. Hence, different alternative sorbents are desirable to overcome these kinds of problems [6].

One of the techniques applied to the treatment of contaminated effluents is sorption using clays, and a wide number of studies have been focused on sorption using calcined or surface modified clays [7] and more specifically organoclays [8-12]. The advantage of using these sorbents is mainly their easy availability, with relatively low cost and large surface area [1]. The sorption of NOCs by organoclays depends on the following factors $[13,14]$ : the structure and size of alkylammonium ions, the type of clay, the cation exchange capacity, the density and orientation of the alkyl chains on the surface, and, features solute size, shape and relative solubility/hydrophobicity. Therefore, the favorable factors would be able to tune thorough the synthesis of design phyllosilicates. In this sense, synthetic organo-functionalized clays are replacing natural smectites and 
vermiculites $[15,16]$. However, all of those synthetic clays have a low cation exchange capacity (CEC).

The materials examined in the present study are a family of synthetic swelling highcharged micas, which has been organo-functionalized with long chain alkylammonium cations. Therefore, the main objective of this work is to analyze the sorption capacity of NOCs by this novel organomica family that allows a methodical analysis of the parameters that influence this procedure. Benzene, toluene and phenol were selected for the study of NOCs sorption since they are known to be the major components of the wastewater from the petroleum refineries.

\section{Experimental}

\subsection{Materials.}

Na-Mica-n ( $\mathrm{n}=3$ and 4) were synthesized using the NaCl-melt as described by Alba et al. [17]. Their structural formulae are $\mathrm{Na}_{n}\left[\mathrm{Si}_{8-\mathrm{n}} \mathrm{Al}_{n}\right] \mathrm{Mg}_{6} \mathrm{O}_{20} \mathrm{~F}_{4}$, where $n$ represent the layer charge ( $\mathrm{n}=3$ and 4). The starting materials employed were $\mathrm{SiO}_{2}$ (Sigma; CAS no. 11294552-5, $99.8 \%$ purity), $\mathrm{Al}(\mathrm{OH})_{3}$ (Riedel-de Haën; CAS no. $21645-51-2,99 \%$ purity), $\mathrm{MgF}_{2}$ (Aldrich; CAS no. 20831-0, 98\% purity), and NaCl (Panreac; CAS no. 131659, 99.5\% purity). Stoichiometric proportions of reactants were weighed and mixed in an agate

mortar. The molar ratio between the reactants were (8$n) \mathrm{SiO}_{2}:(n / 2) \mathrm{Al}_{2} \mathrm{O}_{3}: 6 \mathrm{MgF}_{2}:(2 n) \mathrm{NaCl}$ [18]. The optimal amount of mixture reaction was up to $2 \mathrm{~g}$ that were grinded in an agate mortar during $30 \mathrm{~min}$. They were calcined in a closed Pt crucibles at $900{ }^{\circ} \mathrm{C}$ during $15 \mathrm{~h}$ using at $10^{\circ} \mathrm{C} \cdot \mathrm{min}^{-1}$. The product was washed with distilled water, filtered and dried at room temperature. 


\subsection{Organo-functionalization of micas.}

The organomicas were prepared by a cation-exchange reaction between the micas and concentration of alkylammonium salt to satisfy the 2 times the CEC of Na-Mica-n. Thus, the primary amine was dissolved in an equivalent amount of $\mathrm{HCl}(0.1 \mathrm{M})$ and the resulting mixture stirred for $3 \mathrm{~h}$ at $80{ }^{\circ} \mathrm{C}$. The alkylammonium dispersion was then mixed with 0.6 $\mathrm{g}$ of Na-Mica-n and stirred for $3 \mathrm{~h}$ at $80{ }^{\circ} \mathrm{C}$. After adding hot deionized water, the mixture was stirred for $30 \mathrm{~min}$ at $50{ }^{\circ} \mathrm{C}$ and then the dispersion was centrifuged at $10,000 \mathrm{rpm}$ for 20 minutes. The product was dissolved in a hot ethanol-water mixture (1:1) and stirred for $1 \mathrm{~h}$ at $50{ }^{\circ} \mathrm{C}$ and then centrifuged $[19,20]$. The precipitate was dried at room temperature. The sample will be named as $\mathrm{C}_{\mathrm{m}}$-Mica-n; where $n$ is the layer charge 3 or 4 and $m$ is carbon chain length of the alkylammonium salt $(m=12,14,16$, and 18).

Table 1 shows some properties of the alkylammonium-micas that will be used for the discussion of the results.

\subsection{Sorption of non-ionic organic pollutants.}

Each batch sorption test was prepared in a $250 \mathrm{ml}$ glass bottle, with $0.1 \mathrm{~g}$ of organomica and $100 \mathrm{ml}$ of NOCs (phenol, benzene or toluene) solution in water:ethanol (9:1) at different concentration, $0.2-2.0 \mathrm{mmol}$ of NOCs per gram of organomica. The samples were equilibrated for $12 \mathrm{~h}$ in an orbitals shaker (Unimax-2010) at $260 \mathrm{rpm}$.

The suspensions were centrifuged at 8,000 r.p.m. at $8{ }^{\circ} \mathrm{C}$ for $40 \mathrm{~min}$. The supernatants were withdrawn for NOCs analysis; the difference in the amount before and after sorption reveals the amount of sorbed NOCs $\left(\mathrm{C}_{\mathrm{s}}\right)$ 


$$
C_{s}=\left(C_{i}-C_{e q}\right) \cdot \frac{V}{m}
$$

where the $V(L)$ is the volume of the solution, $m$ is the weight of the mica $(\mathrm{kg}), \mathrm{C}_{\mathrm{i}}(\mathrm{g} / \mathrm{L})$ and $\mathrm{C}_{\mathrm{eq}}(\mathrm{g} / \mathrm{L})$ are the concentration of the organic compounds in initial and final solution, respectively.

Control experiments were performed without organomicas and indicated the negligible loss of NOCs by volatilization or by sorption on the glass tubes.

The sorption percentage and the distribution ratio $\left(\mathrm{K}_{\mathrm{d}}, \mathrm{L} / \mathrm{kg}\right)$, were calculated as follows:

$\%$ Sorption $=\frac{C_{i}-C_{e q}}{C_{i}} \cdot 100$

$K_{d}=\frac{C_{s}}{C_{e q}}$

Normalized $\mathrm{K}_{\mathrm{d}}$ value by organic content present in each organomica, arise organic content corrected coefficient, $\mathrm{K}_{\mathrm{om}}(\mathrm{L} / \mathrm{kg}$ of carbon), calculated according to:

$K_{o m}=K_{d} \frac{f_{o m}}{O C}$

$f_{o m}=\frac{w_{C m}}{w_{C}}$ eq. 5

where OC is the organic carbon (g alkylammonium/g organomica, it is calculated from the weight loss in the temperature range between $170{ }^{\circ} \mathrm{C}$ and $\left.900{ }^{\circ} \mathrm{C}\right), \mathrm{w}_{\mathrm{Cm}}$ is the weight of the alkylammonium cation and $\mathrm{w}_{\mathrm{C}}$ is the weight of carbon in the alkylammonium cation. Thus, $f_{\text {om }}$ is the weight of the alkylammonium cation normalized to the weight of carbon in the alkylammonium cation. Those parameters have been calculated for all organomicas and summarized in Table 1.

\subsection{Techniques.}


The organic contaminant concentration in the initial and final solutions was measured with an UV-vis spectrometer (Shimadzu UV-2101PC) at the wavelength of $254 \mathrm{~nm}$ (benzene) [21], $261 \mathrm{~nm}$ (toluene) [22] and $270 \mathrm{~nm}$ (phenol) [22].

Simultaneous thermogravimetric and thermal measurements (TG/DTA) were performed at the Departamento de Cristalografía, Mineralogía y Química Agrícola (University of Seville, Spain) using a NETZSCH (STA 409 PC/PG) instrument which is equipped with a Pt/Pt-Rh thermocouple for direct measurement of the temperature from RT up to $900{ }^{\circ} \mathrm{C}$ at $10{ }^{\circ} \mathrm{C} / \mathrm{min}$ in an $\mathrm{N}_{2}$ atmosphere. The DTA reference was pure aluminum oxide.

X-ray diffraction (XRD) patterns were obtained at the CITIUS X-ray laboratory (University of Seville, Spain) on a Bruker D8 Advance instrument equipped with a $\mathrm{Cu}$ $\mathrm{K}_{\alpha}$ radiation source operating at $40 \mathrm{kV}$ and $40 \mathrm{~mA}$. Diffractograms were obtained in the $2 \theta$ range of $1-70^{\circ}$ with a step size of $0.05^{\circ}$ and a step time of $3.0 \mathrm{~s}$.

Infrared spectra (FTIR) were recorded in the range $4000-300 \mathrm{~cm}^{-1}$ by the Spectroscopy Service of the ICMS (CSIC-US, Seville, Spain), as KBr pellets, using a Nicolet spectrometer (model 510P) with a nominal resolution of $4 \mathrm{~cm}^{-1}$.

\section{RESULTS AND DISCUSSIONS}

3.1.Influence of the alkylammonium chain length on the phenol sorption by $\mathrm{C}_{m}$-Mica$4(m=12,14,16$ y 18, number of $C$ on the alkyl chain).

The dependence of phenol sorption by $\mathrm{C}_{\mathrm{m}}$-Mica- 4 with the equilibrium concentration (Fig. 1a) is characterized by a non-linear behavior and present two regions. In the first region, at low equilibrium concentrations of phenol, a continuous increase of the amount 
sorbed, followed by a constant sorption, is observed. In the second region, a rapid increase in the concentration sorbed occurs. Similar behavior has been observed in the sorption of phenol by organobentonites [23].

The type of isotherm that is used to describe the sorption data obtained according to the Giles' classification [24] corresponds to the sigmoid shaped isotherm or type S (Fig. 1a). The sigmoidal isotherm shape is exhibited by $\mathrm{C}_{14}$-Mica-4, $\mathrm{C}_{16}$-Mica-4 and $\mathrm{C}_{18}$-Mica4. This sorption isotherm type is due to two mechanisms: one in which the sorption is favored by the attractive forces solute-solute and a cooperative sorption occurs, and another, in which the sorption can be inhibited by a competitive reaction in the solution [25-27]. The isotherms type $S$, are observed when organic compounds are sorbed into covering the surface, allowing other molecules being more readily sorbed, in a model of cooperative sorption [28-30]. However, the isotherms of $\mathrm{C}_{12}$-Mica-4 show the convex upward shape, similar to L-type, which indicates the formation of a solute phase (interlayer sorption of phenol) on the organoclay surface, which serves as additional sorbent [31].

In $\mathrm{C}_{12}$-Mica-4 and $\mathrm{C}_{14}$-Mica-4, greater percentage of phenol sorption is observed in the region of low initial concentrations (Fig. 1b), indicating a high affinity between the sorbent and the sorbate and, therefore, at high initial solute concentrations, the sorption is effectively promoted. In general, the highest affinity is observed in the phenol sorption as the alkylammonium chain length decreases. $\mathrm{C}_{12}$-Mica-4 is the most effective sorbate for phenol removing. Smith et al. [32] demonstrated that small organic cations create a relatively rigid, nonpolar surface amenable to NOC uptake by sorption and, hence, a surface characterized by a relatively high NOC uptake; in contrast, large organic cations create an organic partition medium for NOC uptake that provokes a relatively low NOC uptake. Moreover, Sheng et al. [33] indicated that organoclays have multiple sorptive 
mechanisms and the sorption of aqueous-phase NOCs is controlled by solvation of cationic ammonium centers, the alkyl chain of organic cation, the clay surfaces and solute partitioning.

Table 2 shows the distribution coefficient, $\mathrm{K}_{\mathrm{d}}$, and the normalized coefficient to the organic content, $\mathrm{K}_{\mathrm{om}}$. The $\mathrm{K}_{\mathrm{d}}$ decreases as the alkyl chain increases in parallel with the interlayer water content [19]. According to the values of the logarithms of the normalized sorption coefficients, it is found that the sorption efficiency of organomicas follows the order: $\mathrm{C}_{12}$-Mica-4 $>\mathrm{C}_{14}$-Mica-4 $>\mathrm{C}_{16}$-Mica-4 $>\mathrm{C}_{18}$-Mica-4, indicating that the sorption depends on the chain length of the organic cations. These results agrees with other studies that demonstrated that the sorption efficiency increases as the cation size decreases [34].

Fig. 2 and Fig. 3 show the XRD patterns of the initial $\mathrm{C}_{\mathrm{m}}$-Mica-4 and after phenol sorption. The XRD patterns before phenol sorption indicate a high ordering as the alkyl chain increases (Fig. 2a and Fig. 3a). This fact can explain the trend in the observed $\mathrm{K}_{\mathrm{om}}$ values (Table 2) because $\mathrm{Zhu}$ et al. [35] observed that $\mathrm{K}_{\mathrm{om}}$ value of CTMAmontmorillonite used to sorb naphthalene in water decreased sharply when $\mathrm{CTMA}^{+}$in the interlayer spacing has a high ordering and packing density. After phenol sorption, the main reflection, 001, shows minor changes in the width and moves slightly, however, the organomica remains highly expanded and ordered. Sheng et al. [33], have found that aromatic compounds, due to their flat shape and presence of $\pi$-bond, interact strongly with the organic cation in the organoclay, causing a reorientation of the alkyl chains when alkylammonium cations lie parallel to the sheets of silicate and the alkylammonium adopted a vertical position. In $\mathrm{C}_{\mathrm{m}}$-Mica-4 the organization of the alkylammonium cations corresponds to inclined bilayers [19] and thus, phenol sorption do not affect to the arrangement of alkylammonium cations. 
Stretching IR modes of methyl and methylene groups observed in the range between 2800 and $3000 \mathrm{~cm}^{-1}$ (Fig. 4 and Fig. 5) show a progressive increase in bandwidth with increasing phenol concentration, indicating effects on the ratio of gauche/trans conformations along the aliphatic chains of the organic cation. In the region $675-900 \mathrm{~cm}^{-}$ ${ }^{1}$, a band at $754 \mathrm{~cm}^{-1}, \mathrm{CH}$ bending vibrational mode, is observed in the IR spectra of $\mathrm{C}_{12}$ Mica-4 and $\mathrm{C}_{14}$-Mica-4 after phenol sorption. This band has not been clearly observed on $\mathrm{C}_{16}$-Mica-4 and $\mathrm{C}_{18}$-Mica-4. Xing et al. [36] used biopolymers as sorbents and did not find difference between the infrared spectra of the sorbent after sorption of phenol due to the limited quantities of phenol sorbed on these materials.

\subsection{Role of the layer charge on the phenol sorption by $C_{18}-M i c a-n(n=3$ and 4).}

The dependence of phenol sorption by $\mathrm{C}_{18}$-Mica- 3 and $\mathrm{C}_{18}$-Mica- 4 with the equilibrium concentration is presented in Fig. 1a and the results show a similar trend in the behavior of sorption. It is noted that a change in the shape of the isotherm occurs, about phenol equilibrium concentration of $1 \mathrm{mmol} / \mathrm{L}$, and an increased sorption to high concentrations of phenol is observed; the sorption is slightly greater in the $\mathrm{C}_{18}$-Mica-3.

The percentage of sorbed phenol depends on the initial phenol concentration (Fig. 1b). $\mathrm{C}_{18}$-Mica-4 is more efficient in the sorption of phenol at low concentrations and the opposite occurs at high initial phenol concentration where the $\mathrm{C}_{18}$-Mica-3 is more efficient.

According to the sorption coefficient shown in Table 2, $\mathrm{C}_{18}$-Mica-3 is more efficient than the $\mathrm{C}_{18}$-Mica-4 when the sorption coefficient values are compared for the initial concentration in which the maximum amount of phenol is removed from solution. 
Fig. 3 shows the XRD patterns of the initial $\mathrm{C}_{18}$-Mica-n and after phenol sorption. The XRD patterns show the same trend observed for $\mathrm{C}_{\mathrm{m}}$-Mica-4, where no major change is observed after phenol sorption.

Stretching IR modes of methyl and methylene groups, observed in the range between 2800 and $3000 \mathrm{~cm}^{-1}$, (Fig. 5) show a progressive increase in bandwidth with increasing phenol concentration, indicating effects on the ratio of gauche conformations/trans along the aliphatic chains of the organic cation. The band at $754 \mathrm{~cm}^{-1}, \mathrm{CH}$ bending vibrational mode, is not clearly observed on $\mathrm{C}_{18}$-Mica-n due to the limited quantities of phenol sorbed on these materials [36].

\subsection{Sorption of phenol, benzene and toluene by $C_{18}-M i c a-4$.}

The effect of the nature of the solute was explored by sorbing phenol, benzene and toluene, solved in a mixture of $90 \%$ water and $10 \%$ ethanol, to ensure solubility at high concentrations, on $\mathrm{C}_{18}$-Mica-4. The dependence of the sorbed amount with the equilibrium concentration (Fig. 6a) show a nonlinear behavior. This behavior was previously observed on HDTMA-smectite and it was attributed to that in addition to solute partitioning into de organoclay, solvation of the alkylammonium and the mineral surfaces occur [33]. The percentage of NOCs removed relative to the initial concentration (Fig. 6b) suggest that the removal of toluene and benzene are achieved more efficiently compared with the removal of phenol, reaching levels close to $75 \%$ compared to the initial concentration, as can be seen in Table 2 .

To establish the extent of sorption, the normalized sorption coefficient, $\mathrm{K}_{\mathrm{om}}$, for the initial concentration where the sorption of the NOCs was maximum, is presented in Table 2. The values of the sorption coefficients of benzene are greater than those shown for 
sorption on soil $\left(\log \mathrm{K}_{\mathrm{om}}\right.$ equal to 1.26$)$ and clays modified with hexadecyltrimethylammonium, HDTMA, ( $\log K_{\text {om }}$ between 2.00 and 2.40), indicating the potential used of high-charged organomicas for removing benzene [37]. Similarly, the values of the sorption coefficients of toluene are greater than those shown for the sorption on the raw soil ( $\log \mathrm{K}_{\mathrm{om}}$ equal to 1.39$)$ and soil modified with HDTMA $\left(\log \mathrm{K}_{\mathrm{om}}\right.$ between 2.74 and 2.89), [38] indicating promising application of high-charged organomicas for the removal of toluene from an aqueous solution.

These results show that the coefficient of distribution is influenced by the nature of the solute. Toluene and benzene, exhibit less interaction with the solvent compared to phenol, so that hydrophobic interactions with the surface of the organomica are favored.

The XRD patterns of the C18-Mica-4 after sorption (Fig. 7) are very similar to those of precursor organomica and, in the studied range of concentrations, no significant structural changes occur. The width of the main signal has a tendency to decrease, indicating some degree of order after the sorption process.

\section{Conclusions}

For first time, synthetic high-charged organo-functionalized micas have been evaluated for the sorption of the NOCs pollutants phenol, toluene and benzene.

The $\mathrm{C}_{\mathrm{m}}$-Mica-4 are effective absorbents in removing phenol from aqueous solutions and removal capability is a function of the chain length, the mass fraction and the organization of the organic cation in the structure of the layered silicate.

The efficiency of the sorption of phenol on the $\mathrm{C}_{18}$-Mica-m do not directly depends on the layer charged because it is a function of the initial concentration of phenol. 
$\mathrm{C}_{18}$-Mica-4 can effectively sorb benzene, toluene and phenol, and, the nature of the organic solute and solvent interactions determine the degree of sorption of the organic pollutant.

Therefore, the sorption properties of NOCs by high-charge organomicas can be controlled from the selection of the type of silicate precursor and the chain length of the organic cation. These variables allow modifying the amount of cations that are found in the interlayer space, the structural properties of organic phase, the hydrophobicity conditions and the interactions between the solute-sorbent which are more suitable for the effectiveness of the sorption process.

\section{Acknowledgments}

We would like to thank the Junta de Andalucía (Spain) and FEDER (Proyecto de Excelencia de la Junta de Andalucía, project P12-FQM-567) and to the Spanish State Program R+D +I oriented societal challenges and FEDER (Project MAT2015-63929-R) for financial support. Dra. Pazos thanks financial support to "El patrimonio autónomo fondo nacional de financiamiento para la ciencia, la tecnología y la innovación, Francisco José de Caldas" (FP44842-627-2014). Dr. Pavón thanks her grant to Andalucía Talent Hub Program, co-funded by the EU in 7FP, Marie Skłodowska-Curie actions ( $n^{\circ} 291780$ ) and the Junta de Andalucía. F.J. Osuna thanks his grant to the training researcher program associated to the excellence project of Junta de Andalucía (P12-FQM-567). 
Table 1.

Chemical and structural properties of organomicas

\begin{tabular}{|c|c|c|c|}
\hline $\mathrm{C}_{\mathrm{m}}$-Mica-n & $O C$ & $\begin{array}{c}\% \text { CEC } \\
\text { satisfied by } \\
\text { alkylammonium }\end{array}$ & $f_{o m}$ \\
\hline $\mathrm{C}_{12}$-Mica-4 & 0.45 & 90.75 & 1.29 \\
\hline $\mathrm{C}_{14-\mathrm{Mica}-4}$ & 0.53 & 99.25 & 1.27 \\
\hline $\mathrm{C}_{16}$-Mica-4 & 0.54 & 97.50 & 1.26 \\
\hline $\mathrm{C}_{18}$-Mica-4 & 0.70 & 119.5 & 1.25 \\
\hline $\mathrm{C}_{18}$-Mica-3 & 0.60 & 116.0 & 1.25 \\
\hline
\end{tabular}

Table 2.

NOCs sorption of $\mathrm{C}_{\mathrm{m}}$-Mica-n at $\mathrm{C}_{\mathrm{i}}=1.5 \cdot 10^{-3} \mathrm{~mol} / \mathrm{L}$

\begin{tabular}{lccccc}
\hline & NOCs & $\begin{array}{c}\mathrm{C}_{\mathrm{s}} \\
(\mathrm{mol} / \mathrm{kg})\end{array}$ & $\%$ sor. & $\mathrm{K}_{\mathrm{d}}(\mathrm{L} / \mathrm{kg})$ & $\log K_{\mathrm{om}}$ \\
\hline $\mathrm{C}_{18}$-Mica-3 & phenol & 0.09 & 5.78 & 61.35 & 2.11 \\
$\mathrm{C}_{18}$-Mica-4 & phenol & 0.08 & 5.25 & 55.45 & 2.00 \\
& benzene & 0.78 & 52.02 & 1084.49 & 3.29 \\
& toluene & 1.11 & 74.31 & 2893.07 & 3.71 \\
$\mathrm{C}_{16}$-Mica-4 & phenol & 0.14 & 9.25 & 104.15 & 2.39 \\
$\mathrm{C}_{14}$-Mica-4 & phenol & 0.16 & 10.38 & 115.91 & 2.44 \\
$\mathrm{C}_{12}$-Mica-4 & phenol & 0.17 & 11.53 & 130.28 & 2.57 \\
\hline
\end{tabular}




\section{FIGURES CAPTION}

Fig. 1. a) Phenol sorption $v s$. equilibrium concentration, and, b) percentage of phenol sorption $v s$. initial concentration on $\mathrm{C}_{\mathrm{m}}$-Mica-n.

Fig. 2. XRD patterns of $\mathrm{C}_{\mathrm{m}}$-Mica-4: a) as made, and, after the sorption of phenol: $b$ ) $\mathrm{C}_{\mathrm{i}}=2 \cdot 10^{-4} \mathrm{~mol} / \mathrm{L}$ and c) $\mathrm{C}_{\mathrm{i}}=1.5 \cdot 10^{-3} \mathrm{~mol} / \mathrm{L}$.

Fig. 3. XRD patterns of $\mathrm{C}_{18}-\mathrm{Mica}-\mathrm{n}$ : a) as made, and, after the sorption of phenol: $\mathrm{b}$ ) $\mathrm{C}_{\mathrm{i}}=2 \cdot 10^{-4} \mathrm{~mol} / \mathrm{L}$ and c) $\mathrm{C}_{\mathrm{i}}=1.5 \cdot 10^{-3} \mathrm{~mol} / \mathrm{L}$.

Fig. 4. IR/FT spectra of $\mathrm{C}_{\mathrm{m}}$-Mica-4: a) as made, and, after the sorption of phenol: b) $\mathrm{C}_{\mathrm{i}}=2 \cdot 10^{-4} \mathrm{~mol} / \mathrm{L}$ and c) $\mathrm{C}_{\mathrm{i}}=1.5 \cdot 10^{-3} \mathrm{~mol} / \mathrm{L}$.

Fig. 5. IR/FT spectra of $\mathrm{C}_{18}-\mathrm{Mica}-\mathrm{n}$ : a) as made, and, after the sorption of phenol: b) $\mathrm{C}_{\mathrm{i}}=2 \cdot 10^{-4} \mathrm{~mol} / \mathrm{L}$ and c) $\mathrm{C}_{\mathrm{i}}=1.5 \cdot 10^{-3} \mathrm{~mol} / \mathrm{L}$.

Fig. 6. a) Phenol, benzene and toluene sorption vs. equilibrium concentration, and, b) percentage of phenol, benzene and toluene sorption $v s$. initial concentration on $\mathrm{C}_{18}$-Mica4.

Fig. 7. XRD patterns of $\mathrm{C}_{18}$-Mica-4 after the sorption of a) phenol, b) benzene, and c) toluene at $\mathrm{C}_{\mathrm{i}}=1.5 \cdot 10^{-3} \mathrm{~mol} / \mathrm{L}$. 
Fig. 1
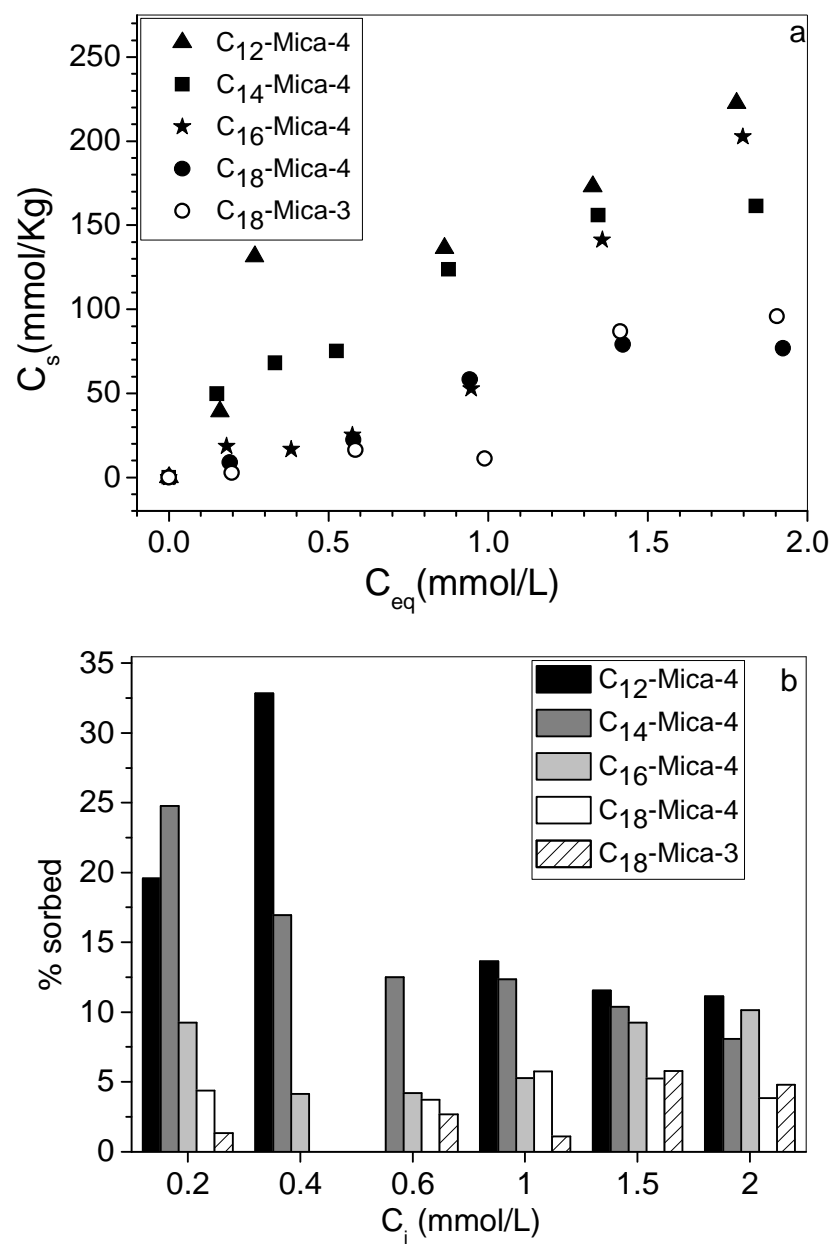
Fig. 2
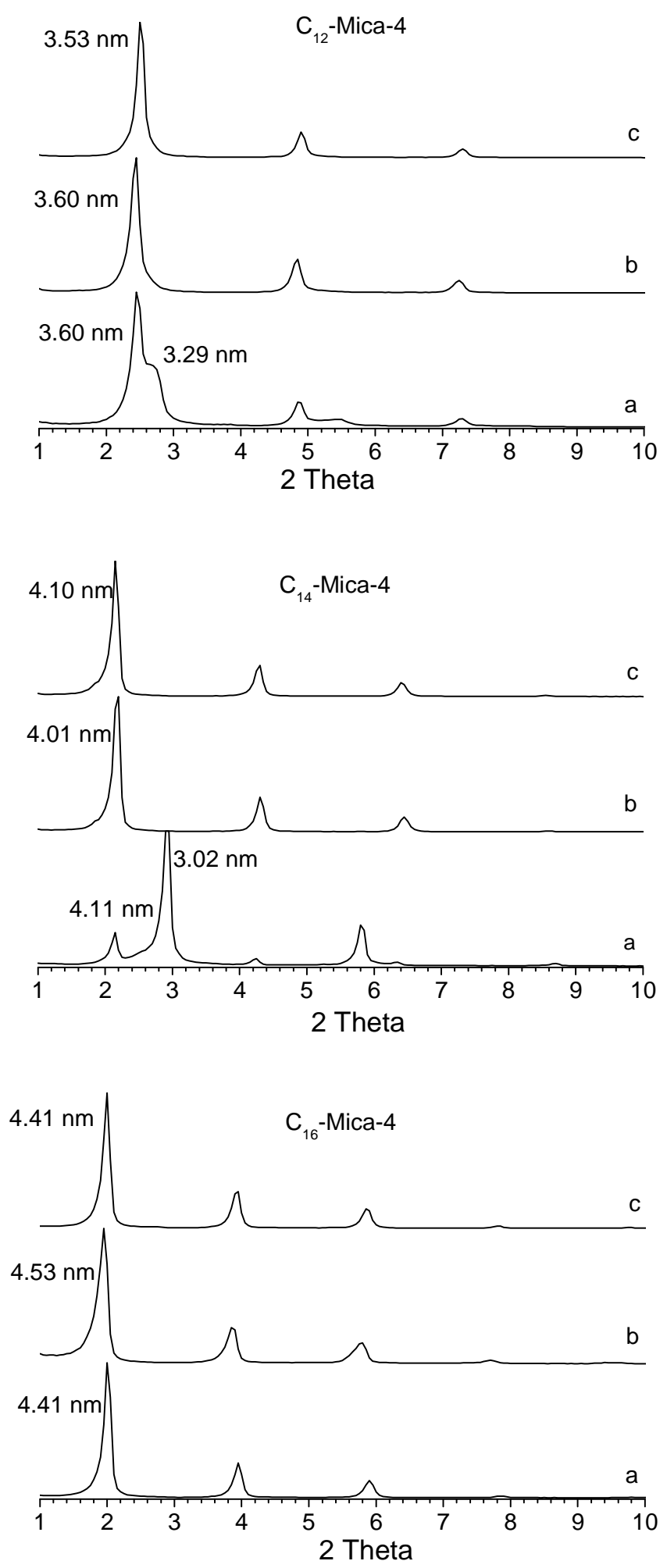
Fig. 3
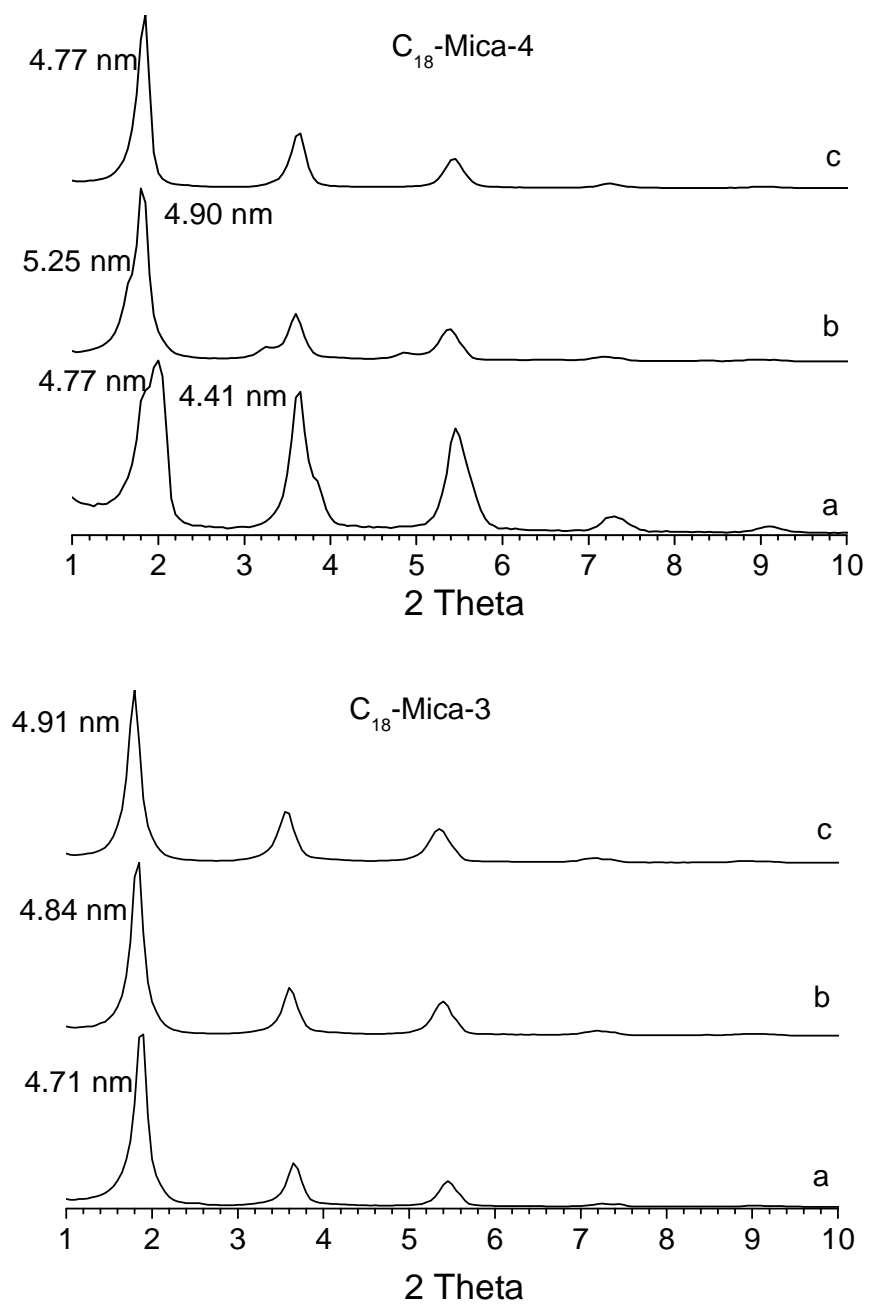
Fig. 4
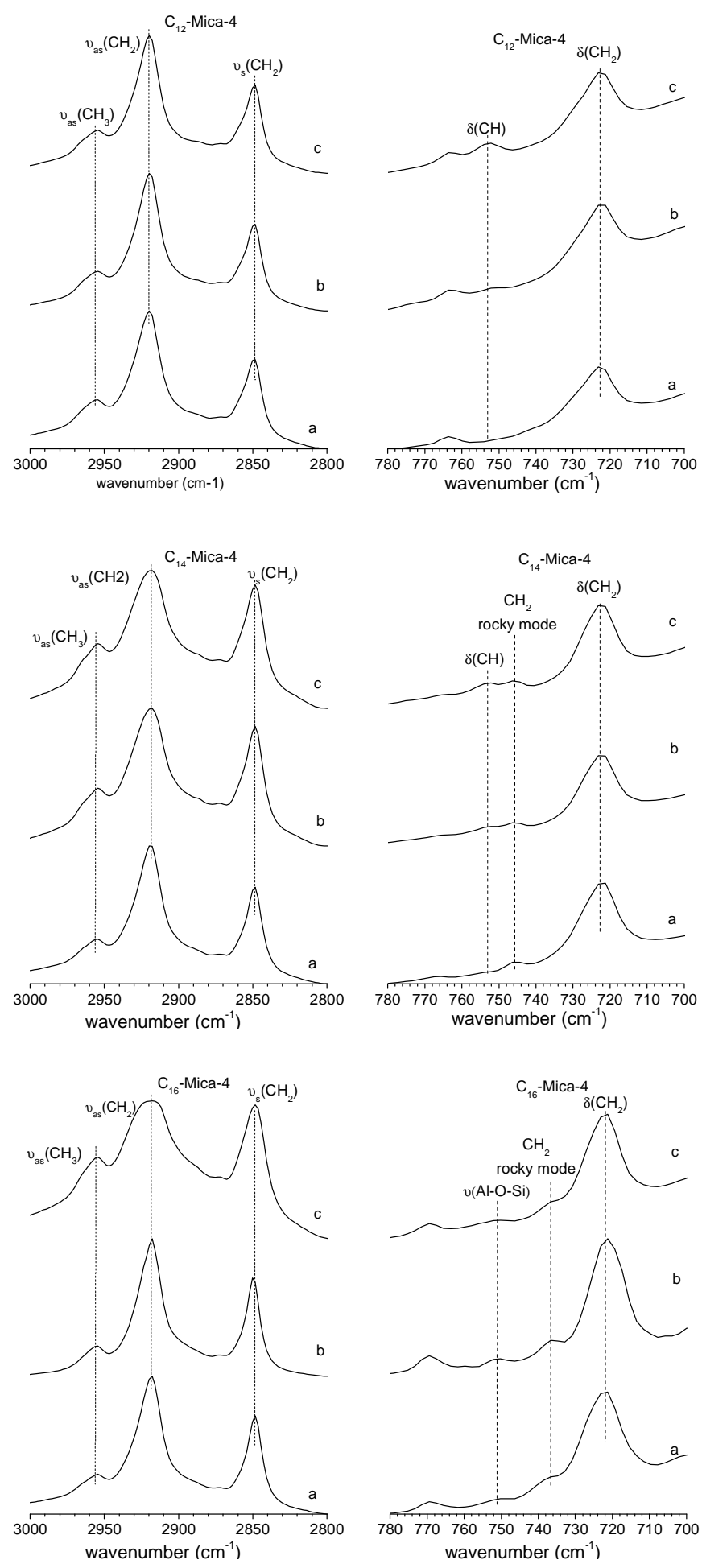
Fig. 5
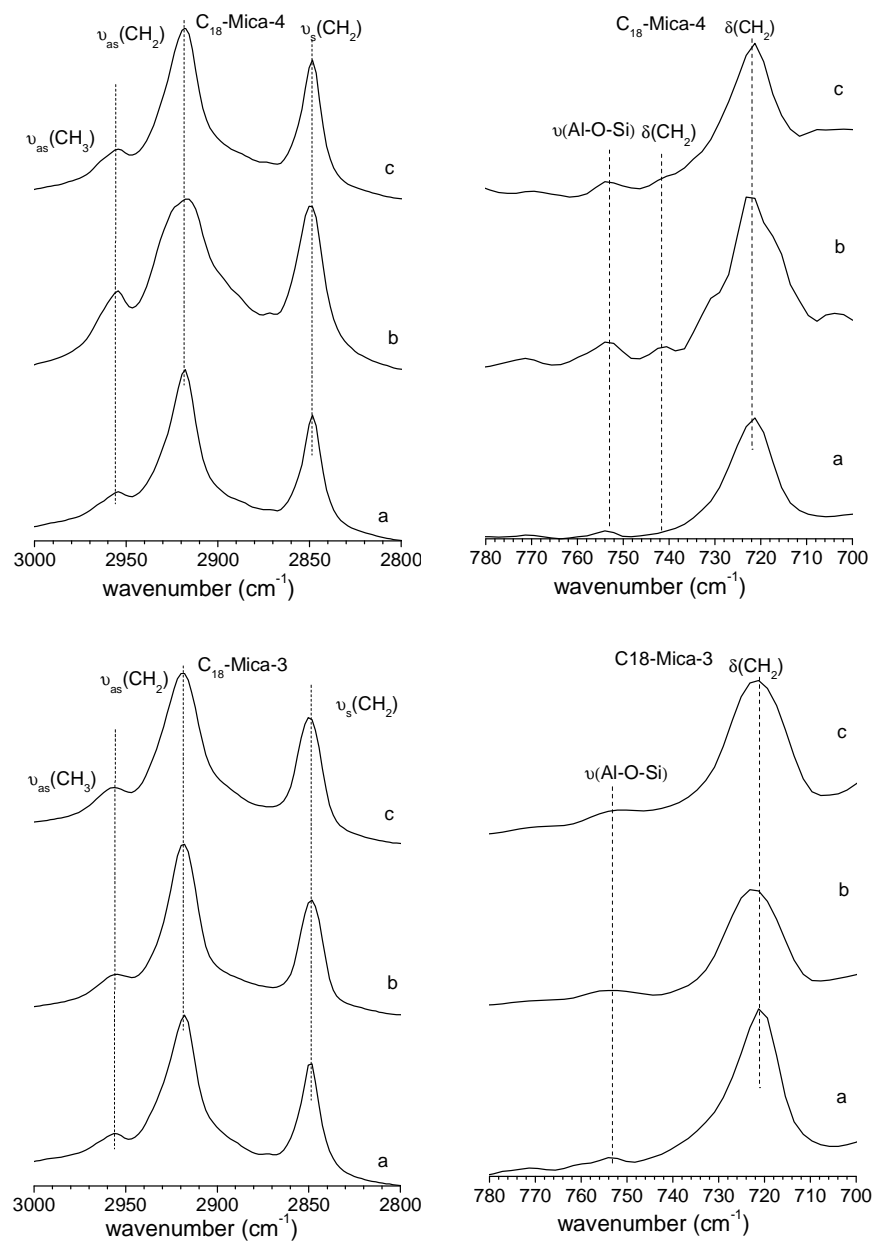
Fig. 6
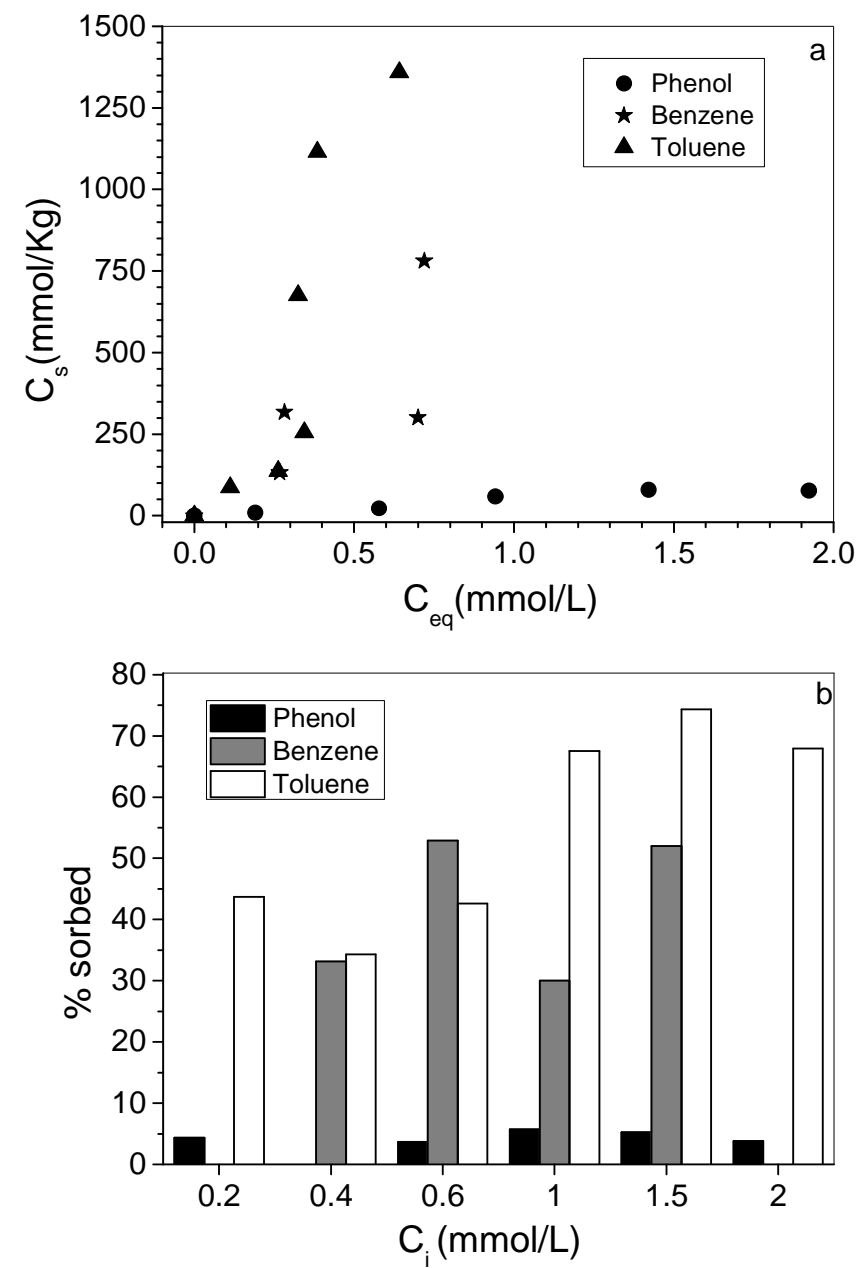
Fig. 7

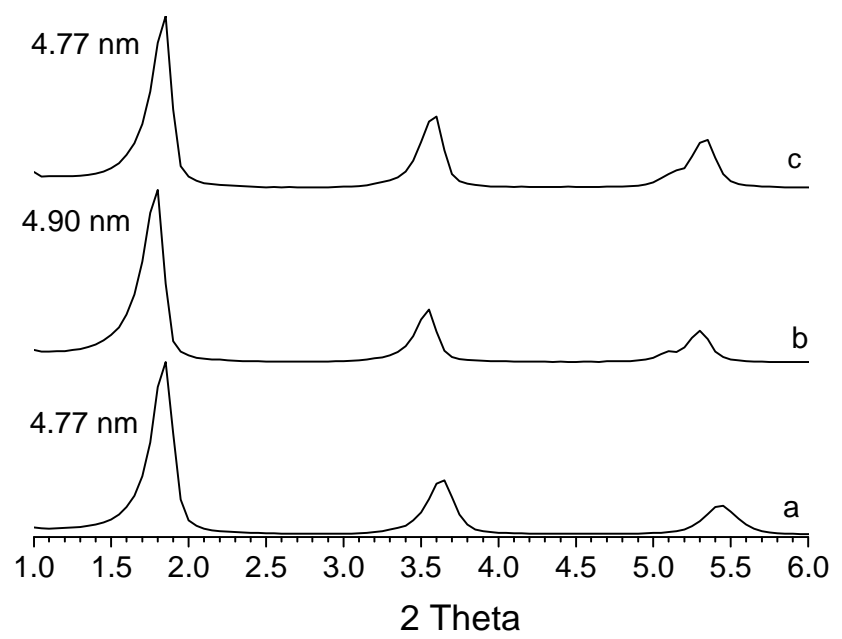


GRAPHICAL ABSTRACT

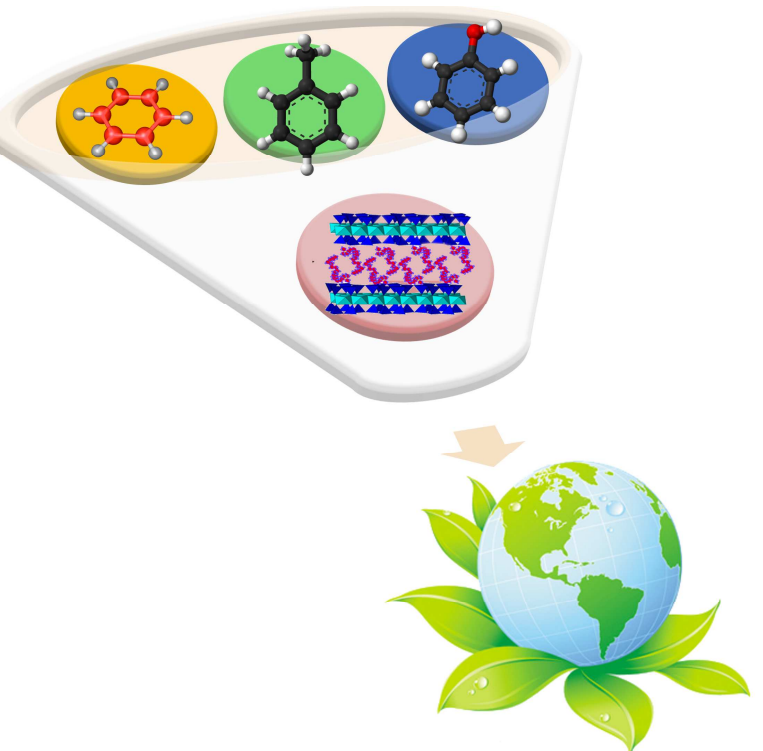




\section{References}

[1] F. Qu, L.Z. Zhu, K. Yang, J. Hazard. Mater. 170 (2009) 7-12.

[2] S.D. Manjare, A.K. Ghoshal, Ind. Eng. Chem. Res. 45 (2006) 6563-6569.

[3] S.J. Yu, X.X. Wang, Y.J. Ai, X.L. Tan, T. Hayat, W.P. Hu, X.K. Wang, J. Mater. Chem. A 4 (2016) 5654-5662.

[4] Z.X. Jin, X.X. Wang, Y.B. Sun, Y.J. Ai, X.K. Wang, Environ. Sci. Technol. 49 (2015) 9168-9175.

[5] H. Zaitan, D. Bianchi, O. Achak, T. Chafik, J. Hazard. Mater. 153 (2008) 852-859.

[6] Q. Hu, J.J. Li, Z.P. Hao, L.D. Li, S.Z. Qiao, Chem. Eng. J. 149 (2009) 281-288.

[7] Y.D. Zou, X.X. Wang, Z.S. Chen, W. Yao, Y.J. Ai, Y.H. Liu, T. Hayat, A. Alsaedi, N.S. Alharbi, X.K. Wang, Environ. Pollut. 219 (2016) 107-117.

[8] C.H. Ko, C. Fan, P.N. Chiang, M.K. Wang, K.C. Lin, J. Hazard. Mater. 149 (2007) 275-282.

[9] S. Richards, A. Bouazza, Appl. Clay Sci. 37 (2007) 133-142.

[10] P.A. Mangrulkar, S.P. Kamble, J. Meshram, S.S. Rayalu, J. Hazard. Mater. 160 (2008) 414-421 .

[11] C.D. Nunes, J. Pires, A.P. Carvalho, M.J. Calhorda, P. Ferreira, Microporous Mesoporous Mat. 111 (2008) 612-619.

[12] A. Khenifi, B. Zohra, B. Kahina, H. Houari, D. Zoubir, Chem. Eng. J. 146 (2009) 345-354.

[13] S. Gitipour, M.T. Bowers, W. Huff, A. Bodocsi, Spill Sci. Technol. Bull. 4 (1997) $155-164$.

[14] R.W. Gullick, W.J. Weber, Environ. Sci. Technol. 35 (2001) 1523-1530.

[15] Z. Klapyta, T. Fujita, N. Iyi, Appl. Clay Sci. 19 (2001) 5-10.

[16] Z. Klapyta, A. Gawel, T. Fujita, N. Iyi, Clay Min. 38 (2003) 151-160. 
[17] M.D. Alba, M.A. Castro, M. Naranjo, E. Pavon, Chem. Mat. 18 (2006) 2867-2872.

[18] A. Esfandiari, H. Nazokdast, A.S. Rashidi, M.E. Yazdanshenas, Journal of Applied Sciences 8 (2008) 545-561.

[19] M.D. Alba, M.A. Castro, M.M. Orta, E. Pavon, M.C. Pazos, J.S.V. Rios, Langmuir 27 (2011) 9711-9718.

[20] M.C. Pazos, M.A. Castro, M.M. Orta, E. Pavon, J.S.V. Rios, M.D. Alba, Langmuir 28 (2012) 7325-7332.

[21] M. Davoudinejad, S.A. Ghorbanian, Scientific Research and Essay 8 (2013) 22632275.

[22] M. Ghiaci, A. Abbaspur, R. Kia, F. Seyedeyn-Azad, Sep. Purif. Technol. 40 (2004) 217-229.

[23] L.H. Xu, L.Z. Zhu, Colloid Surf. A-Physicochem. Eng. Asp. 307 (2007) 1-6.

[24] C.H. Giles, T.H. Macewan, S.N. Nakhwa, D. Smith, J.Chem. Soc. (1960) 3973-3993.

[25] C. Hinz, Geoderma 99 (2001) 225-243.

[26] G. Limousin, J.P. Gaudet, L. Charlet, S. Szenknect, V. Barthes, M. Krimissa, Appl. Geochem. 22 (2007) 249-275.

[27] B.L. Sawhney, CMS Workshop Lectures, Sorption and Desorption of Organic Contaminants by Clays and Soils, The Clay Minerals Society Boulder, 1996.

[28] W.F. Jaynes, G.F. Vance, Soil Sci. Soc. Am. J. 60 (1996) 1742-1749.

[29] M.M. Mortland, S. Shaobai, S.A. Boyd, Clay Clay Min. 34 (1986) 581-585.

[30] M. Akcay, J. Colloid Interface Sci. 296 (2006) 16-21.

[31] S. Lee, A.H. Oren, C.H. Benson, K. Dovantzis, J. Geotech. Geoenviron. Eng. 138 (2012) 115-127.

[32] J.A. Smith, P.R. Jaffe, C.T. Chiou, Environ. Sci. Technol. 24 (1990) 1167-1172.

[33] G.Y. Sheng, S.H. Xu, S.A. Boyd, Environ. Sci. Technol. 30 (1996) 1553-1557. 
[34] J.F. Lee, M.M. Mortland, C.T. Chiou, D.E. Kile, S.A. Boyd, Clay Clay Min. 38 (1990) 113-120.

[35] R.L. Zhu, L.Z. Zhu, J.X. Zhu, L.H. Xu, Sep. Purif. Technol. 63 (2008) 156-162.

[36] B.S. Xing, W.B. McGill, M.J. Dudas, Y. Maham, L. Hepler, Environ. Sci. Technol. 28 (1994) 466-473.

[37] S.A. Boyd, M.M. Mortland, C.T. Chiou, Soil Sci. Soc. Am. J. 52 (1988) 652-657.

[38] J.F. Lee, J.R. Crum, S.A. Boyd, Environ. Sci. Technol. 23 (1989) 1365-1372. 